\title{
Optimization OF HVAC COORDINATION WITH USE OF BIM
}

\author{
Bc. Tomáš Katolický*1, Ing. arch. Robert Bouška² \\ ${ }^{1}$ Czech Technical University in Prague, Thákurova 7 , Prague, 16629, Czech Republic, \\ tomas.katolicky@fsv.cvut.cz \\ ${ }^{2}$ Czech Technical University in Prague, Thákurova 7, Prague, 16629, Czech Republic, \\ robert.bouska@cvut.cz
}

\begin{abstract}
The article deals with the optimization of HVAC design coordination using building information modeling (BIM). The aim is to identify and compare ways of coordination in construction projects and to evaluate BIM method for clash detection. This method is verified by clash detection of HVAC design in practice using the BIM tool Trimble Connect. 3D clashes are detected between different project models according to selected parameters. The result is a quick and accurate identification of clashes. Timely solution prevents cost increases and schedule shifts of the construction project.
\end{abstract}

\section{Keywords}

BIM; Building information modeling; clash detection; coordination; HVAC.

\section{JEL Classification}

L74 Construction

DOI: https://doi.org/10.14311/bit.2020.03.07

Editorial information: journal Business \& IT, ISSN 2570-7434, CreativeCommons license (c) (1) published by CTU in Prague, 2020, http://bit.fsv.cvut.cz/ 


\section{Introduction}

The development of information and communication technologies strongly supports change in most sectors of the national economy. Allows you to transfer a large amount of information and procedures in digital form, share them among users, and use them for analysis, simulation, and control. This digitalization has become significantly more applicable in the construction sector in recent years.

An important part of the digitization of the construction industry is the method of building information modeling (BIM), which concentrates in a shared data environment (CDE), all the necessary graphical and descriptive information into a single complex digital system, which integrates the procedures and algorithms associated with the construction project. It thus contributes to improving cooperation, coordination, exchange of information, control, and decision-making throughout the life cycle of buildings from their preparation, implementation, operation to liquidation. It also includes links to other areas, such as the land register or electronic approval of buildings.

\section{Stage of BIM implementation}

Implementation of BIM is solved according to the local conditions of the country, but there is an effort to share experience and coordinate within Europe. That is why the EU BIM Task Group has been set up to draw up common recommendations based on the experience of individual EU Member States in the "Handbook for the Implementation of Information Modeling of Buildings by the European Public Sector" [1] containing strategic measures to increase construction performance and implementation recommendations. The common European concept is followed by the concept of introduction of the BIM method in the Czech Republic [2], the aim of which is the gradual introduction of this method into construction practice in the years 2018-2027. The concept is organized by the Ministry of Industry and Trade in cooperation with Czech office for standards, metrology and testing (ÚNMZ). The statesubsidized organization Czech Standardization Agency (CAS) established by ÚNMZ was entrusted with the implementation of the measure. The key deadline is 2022, when there will be an obligation to use BIM for above threshold public works contracts financed by public budgets, including the preparation and implementation documentation. The current state of work is listed on the website of the CAS dedicated to the concept of BIM in the Czech Republic [3].

\section{Main impacts of BIM on projects}

\section{Rules}

In projects with a high level of coordination, a definition of rules/standards is needed that all participants will adhere to and which will be independent of the profession, SW or HW. These rules are set by technical standards that define the requirements for the conduct of activities and the quality of their outputs (products, services and buildings). This includes for example the ČSN EN ISO 16739 "Industry Foundation Classes (IFC) data format for data sharing in construction and facility management", or a number of ČSN EN ISO 16757-x standards "Data structures for electronic product catalogues for building services".

\section{Central storage}

BIM model contains a database of data and information about the construction designed for its implementation and subsequent operation. It is a digital twin of the real construction. This information makes it possible to identify states where different building elements show different collisions after they have been assembled. The data model in BIM contains not only spatial data (3D), but also data 
related to time (4D), cost (5D), sustainability (6D) and facility management (7D) [4]. Figure 1 shows these so-called BIM model dimensions.
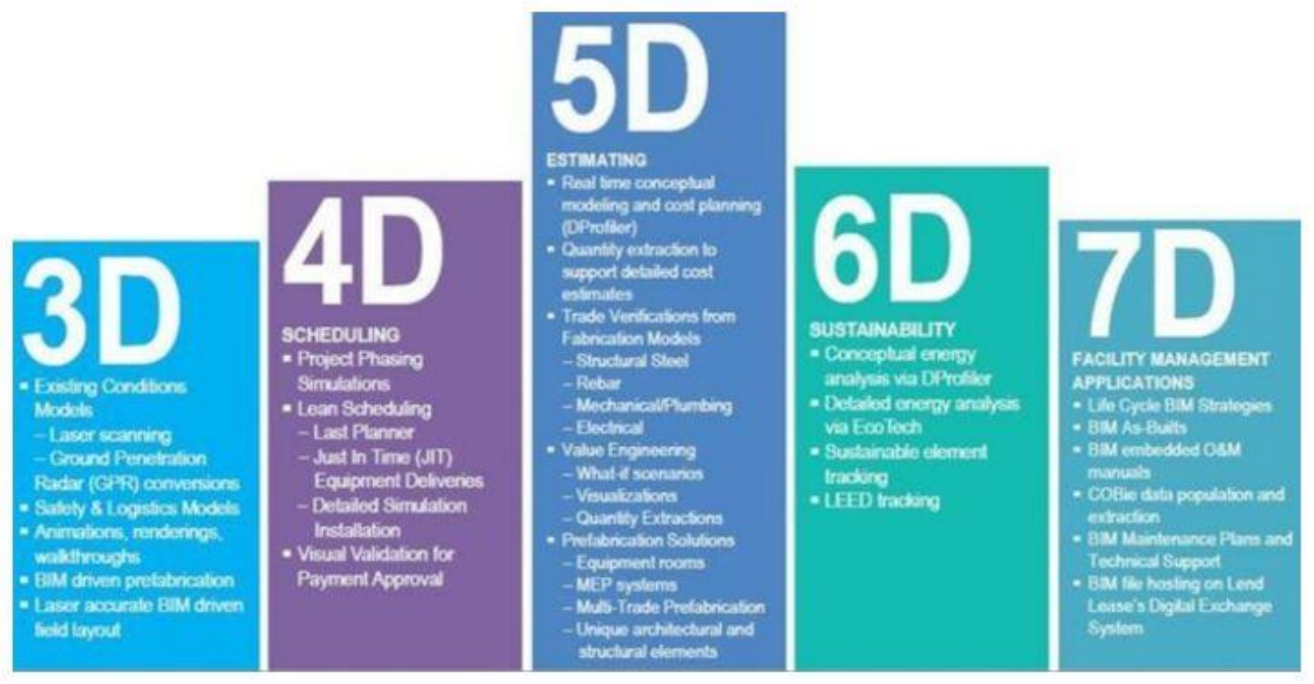

Figure 1: Dimensions of BIM data model, [4]

\section{Model detail}

With a high level of cooperation and communication within the project, it is necessary for the interested parties to agree on the level of detail of their submodels at the individual stages of the construction design. Each level is described in terms of geometry detail, accuracy and range of data about each object. It is usually based on a standard made by the American Institute of Architects. It specifies the individual level of development (LOD) according to the stage at which the project is located (from LOD 100 for the Feasibility Study to LOD 500 for documentation of Actual Implementation).

\section{Information}

The project team creates one common 3D parametric model, which uses to generate each type of documentation. Schedules, sections, views and acreage statements are a byproduct of this common model. It also provides supporting documents for analyses and simulation, such as spatial arrangement, energy performance, use of daylight or material use.

\section{Coordination}

This method of creating documentation requires significantly greater coordination between all activities so that individual professions follow up with their work in the correct order, prepare data in the right detail, transmit data to the Central data environment (CDE) at the right time, modify their parts always in cooperation with the follow-up professions and solve possible clashes in the drawing (3D), time (4D) and cost (5D) already at the design stage [5].

\section{Software tools}

To effectively support the BIM process, it is necessary to correctly select the software tools of each party in advance to communicate with the central database, provide sufficiently detailed data, use the same object libraries, and allow data checks in submodels. Examples frequently used are Navisworks Manage, Solibri Model Checker or Trimble Connect.

Autodesk Navisworks Manage includes advanced features for automatic clash detection. After entering the geometric data, the system examines the entire model and finds any problems and 
conflicts. This search can also be linked to 4D simulation and object animation, which makes it easy to analyze the problem not only in a given space, but also in time. In addition to finding clashes Navisworks Manage also offers tools for managing them, where it is possible to export a report with a detailed view of the collision site, which is then forwarded to the entire work team to resolve the detected clashes. The program supports most design formats.

Solibri Model Checker is another of the programs designed to check the BIM model, which analyzes the correctness of the technical implementation of the project, and checks compliance with the requirements of standards and other regulations. The system allows easy visualization, checks the model of the building, as well as distinguishes possible collisions and shortcomings. It offers daily updated costing, transparent project management, and accurate planning. Solibri Model Checker has a large number of rules to choose from that need to be set up for proper functionality. Initially, it is more difficult to learn how to work with it, but then it allows you to perform more versatile checks than other mentioned programs. IFC, DWG file formats are supported.

Trimble Connect is the successor to TeklaBIMsight from 2020. Trimble Connect is a modern and affordable tool for collaborating and sharing information about BIM projects, supporting teamwork, sharing graphical and descriptive data, and the necessary project information. It can be used in both online and offline mode, using cloud solutions with high data security, the size of the data store is not limited. It keeps a history of all activities on the project, allows you to assign and manage tasks, and display their lists as part of deadlines. It supports effective clash management and early detection. As mentioned earlier, this can reduce construction problems, save time, avoid additional repair and remediation costs. The software includes a 3D BIM browser allowing you to open models in various file formats (IFC, SKP, DWG/ DXF, RVT, etc.).

\section{Competence}

Given the complexity of the BIM data model, new skills and knowledge should be provided. In particular for coordination, data analysis and control. One of the most important steps to successfully implement the project using BIM is to fill the role of BIM coordinator. It must understand the process of implementation, information flows and continuity between professions. It keeps an perspective over the whole project and convinces both internal and external project participants to cooperate. In addition to sufficient knowledge and experience, it also maintains object libraries, manages project data and their communication, coordinates ongoing model changes, and impacts information or professions and ensures ongoing checks [5].

Each stakeholder should appoint at least one BIM worker responsible for its area of activity. This worker cooperates closely with the BIM coordinator, he is an expert in information management, modeling, and specific SW tools of the supplier. Furthermore, it is responsible for the connectivity of software tools to the CDE [6].

\section{Document management}

The objectives and outputs of the project and all the above aspects, including the time requirements for managing and coordinating the progress of BIM work, should include the BIM Execution Plan (BEP). Its importance increases with a number of stakeholders and professions. The purpose of the BEP is to summarize basic information on the creation and work with the BIM model at each stage of the construction life cycle. It clarifies people, responsibilities, organization, processes, defines data, information and how to share it. BEP must be prepared immediately after the decision on the preparation of the construction project using the BIM method. The actual work on the project should begin only after the BEP has been drawn up and the individual stakeholders, teams, and professions have been trained [7]. 


\section{Cybersecurity}

For BIM projects, it is also important to ensure strong data security against various cyber threats. The authorization of access to this environment by individual parties and the secure transfer of data between $C D E$ and a local repository must be addressed. The specification of information protection against loss, damage or misuse (e.g., access rights, communication protocols, security on both sides, liability) should be part of the contract.

\section{Project collisions}

A construction project is a complex process involving many companies, work teams and professions. The project generates a large amount of information and data that needs to be coordinated and exchanged between all stakeholders. Especially in the preparatory phase of the construction, poor coordination may result in clashes between individual parts of the construction, causing its delay and resell. Their cause during the preparation and implementation of the construction is, in addition to the complexity of the design and poor communication, the lack of time or experts, the use of incorrect or low levels of detail, non-compliance with design rules, errors or inaccuracies, occasionally use of various drawing formats. Special tools assist in checking the project model, identifying and reporting conflicts. They provide detection based on geometric and rule-based algorithms, significantly improving the process in terms of speed and accuracy, with greater emphasis on accuracy. This is conditional on the great detail of the data in the BIM model, where several sub-models of individual professions are part of one main one [8]. It also uses detailed information related to the planning, construction, and operation of elements or systems. As a result, it enables the modelling and detection of collisions from spatial (3D), time (4D), cost (5D), sustainability (6D) and facility management (7D) data. 3D collisions are clashes in the spatial arrangement of individual objects with each other. 4D collisions occur when there are problems with compliance with the timetable or coordination of work and supplies that could have an impact on the ongoing implementation. The cause of their occurrence is inconsistency. Among the 4D collisions, we include poorly designed construction site equipment from the point of view of handling space for heavy mechanization and trucks, accumulation of material, unprepared workplace for the onset of the next work crew or collision of lifting equipment with newly built scaffolding [9]. Collisions in dimension 5D relate to noncompliance with the financial plan, cashflow and project costs, often due to additional changes or adjustments to the schedule.

\section{Coordination of designer work}

To optimize coordination with the use of BIM, it is necessary to ensure that the contractor's implementation team cooperates with the team of designers already at the design stage. An excellent knowledge of the use of BIM for all parties involved should therefore be a necessity.

After the completion of the architectural study, negotiations between the investor, architect, designer and contractors could already begin to understand each other and eliminate any misunderstandings in the requirements. At this stage, the architect should deliver the drawings and the BIM coordinator should establish a CDE. Subsequently, the chief designer should create a 3D model. After specifying the conditions, the team of designers could already work on a more detailed model.

When gradually completing individual parts of a building (for example, a building floor), BIM should detect clashes, deficiencies and design errors. Suggestions for their elimination should be made for the problems identified. The chief designer, project manager and architect should then agree on the priorities of the identified problems and decide on the final way to solve them. Priority should be given to resolving situations with an impact on the scope, quality, costs and deadlines of the project. In the event of additional change requests from interested parties, the above procedure should be repeated. 
Subsequently, the team of designers would already modify the detailed models so that several parts of the project are worked on at the same time and are gradually completed collision solving and validation. Potentially most conflicts occur in the technical equipment of buildings (engine rooms), therefore it is necessary in this case to coordinate activities the most. At the same time as the release of individual parts, suppliers can prepare their deliveries for construction.

MEP (Mechanical, Engineering and Plumbing) designers will gradually start working on detailed models. The HVAC (Heating, Ventilation and Air-conditioning) designers should be the first to participate. When the structural design of a part of the building is completed, it can start designing its detailed drawings. The next profession should be plumbing. As in the previous case, the involvement should occur during the design of the previous part, but only in areas already completed. Electrical wiring follows, and the piping of sprinklers should be the last to be projected.

Regular (usually weekly) meetings between the chief designer, the project manager and the BIM coordinator are an important aspect of project coordination. The subject matter of these meetings should be the procedure and coordination of the work in such a way that the project is carried out smoothly without delay, with the minimization of errors and without increasing costs.

\section{Example of the clash detection}

Before you can run a clash detection, you must set the required parameters (Figure 2).

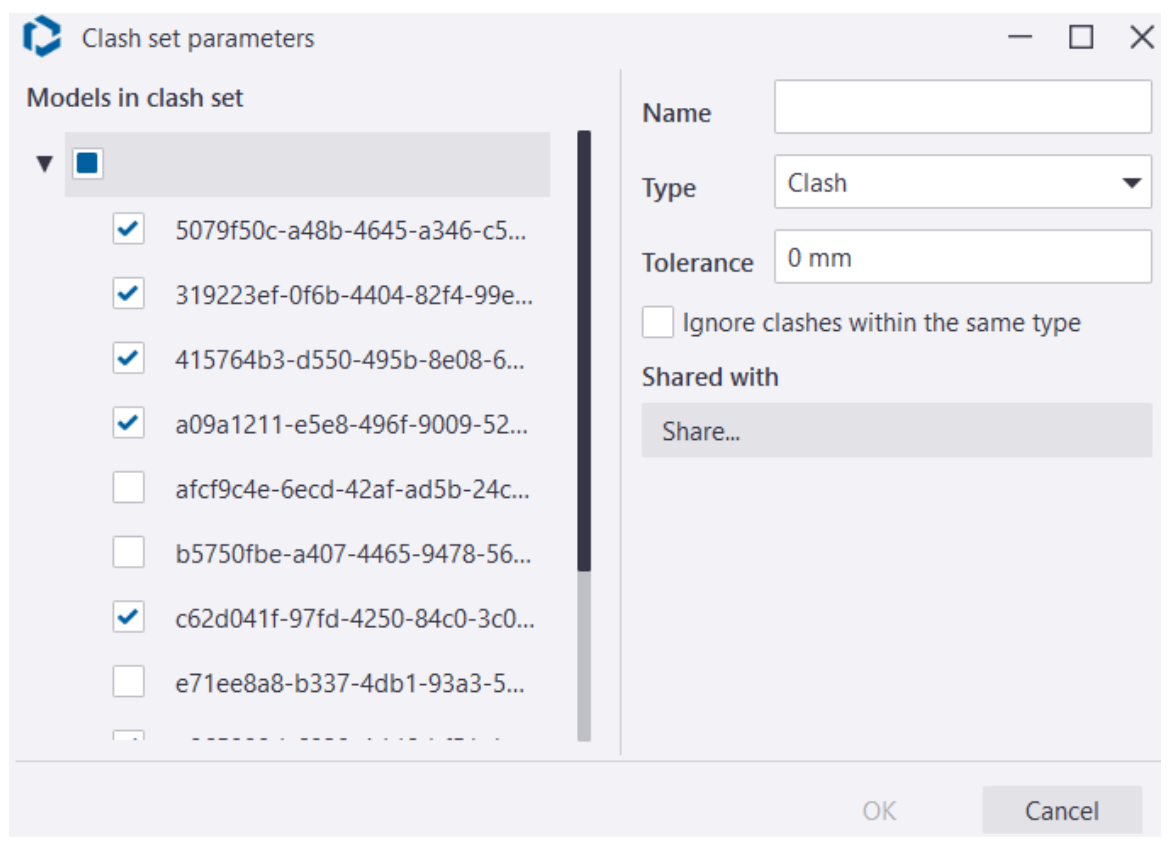

Figure 2: Setting clashes parameters, [authors]

First, the models are selected between which identification will be performed. In addition, tolerances (in the order of $\mathrm{mm}, \mathrm{cm}, \mathrm{dm}$ or $\mathrm{m}$ ) are selected to clash detection between objects, it is defined whether the result should be only hard or even soft clashes (Figure 3 ) and at what distance from each other. You can then set whether to search for all collisions of the same type. These parameters affect the resulting number of detected clashes, which can be units, tens, hundreds and thousands. 


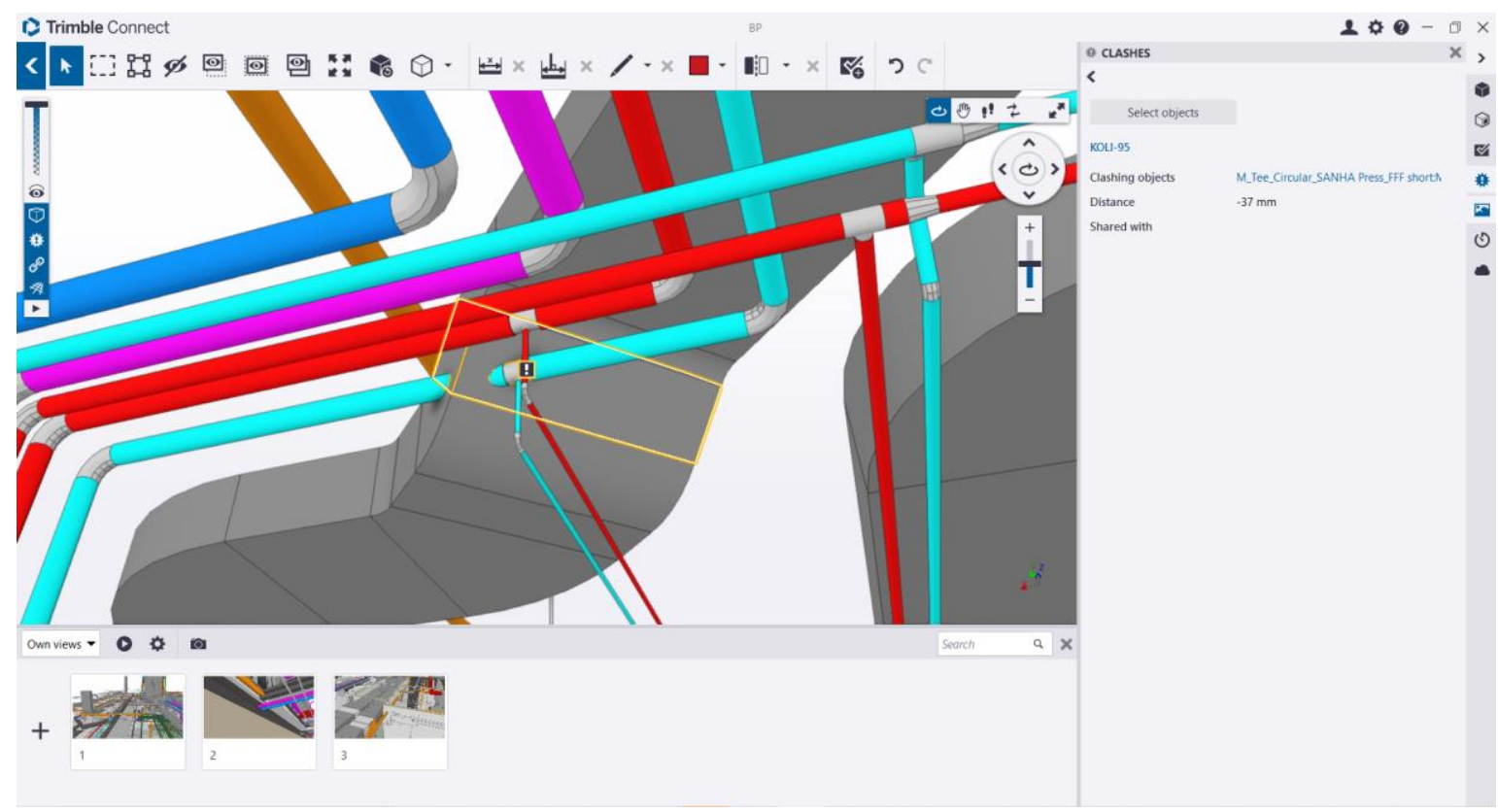

Figure 3: Example of the MEP clash, [authors]

The list of detected clashes selects a specific one that contains a reference to the problem location in the model and highlights which elements are in conflict. At the same time, information about the name of each element in the collision, the length of the collision subjects and the sharing of data with other project participants are displayed (Figure 4).

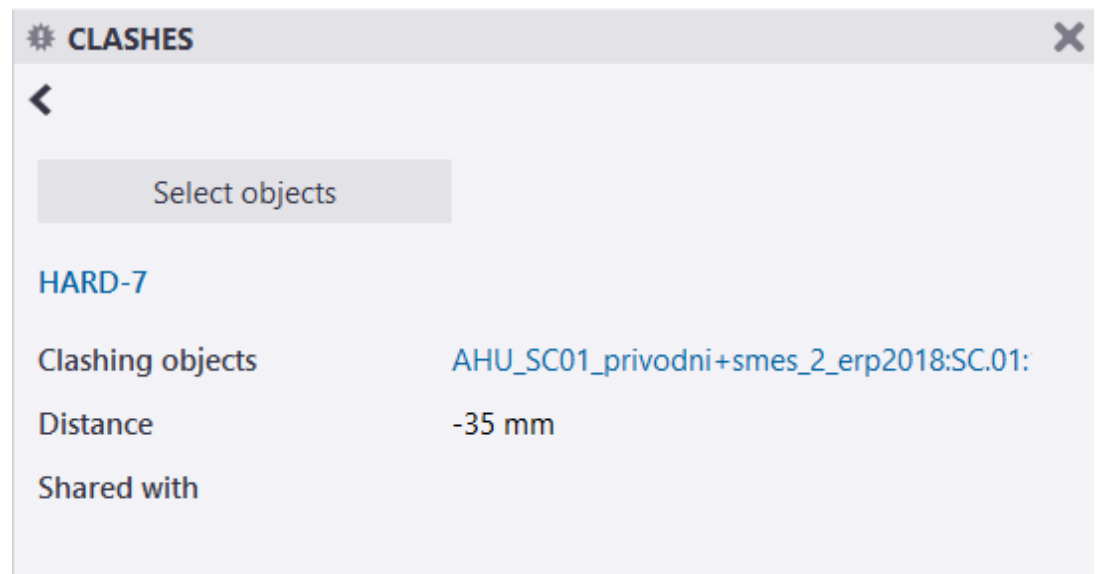

Figure 4: Information of the selected clash, [authors]

For more detailed information about objects, just choose the selected element and then the overall description containing, e.g., name, material, geometric proportions and technical properties is displayed (Figure 5). This data is inserted by the designer/structural designer/architect and consultation with the responsible person is necessary to eliminate the clashes.

The item To-Dos (Figure 6) is a means of communication between all stakeholders. To resolve clashes with other participants, you must provide a comment that contains the name, description of the clash, degree of priority, date of resolution requested, type of clash, status of the solution, procedure, percentage completion, as well as connect an attachment with your own suggestion or query. 


\begin{tabular}{|c|c|c|c|c|c|}
\hline \multicolumn{3}{|l|}{ OBJECTS } & \multicolumn{2}{|l|}{$X$ ОВJЕСТS } & \\
\hline \multicolumn{2}{|l|}{$<$} & & \multicolumn{2}{|l|}{$<$} & \\
\hline Zoom to Object & Select Object & & Zoom to Object & Select Object & \\
\hline \multicolumn{3}{|l|}{ Covering } & \multicolumn{2}{|l|}{ Covering } & \\
\hline \multicolumn{2}{|l|}{ ReferenceObject } & & \multicolumn{2}{|l|}{ Rodina a typ: } & Izolace potrubi:: Thermal Insulatior \\
\hline \multicolumn{2}{|l|}{ GUID (MS): } & b3114874-2144-4540-8c5f-c394df & \multicolumn{2}{|l|}{ Typ: } & Izolace potrubí: Thermal Insulatior \\
\hline \multicolumn{2}{|l|}{ GUID (IFC): } & 2p4KXq8KH5G8nVmvJV5vly & \multicolumn{2}{|l|}{ Jiné } & \\
\hline \multicolumn{2}{|l|}{ File Format: } & Ifc & \multirow{2}{*}{\multicolumn{2}{|c|}{ Kategorie: }} & \\
\hline \multicolumn{2}{|l|}{ Common Type: } & Covering & & & Izolace potrubí \\
\hline \multicolumn{3}{|c|}{ IfcRectangleProfile } & \multicolumn{2}{|l|}{ IfcMaterial } & Izolace potrubi \\
\hline \multicolumn{2}{|c|}{ ProfileName: } & Thermal Insulation 40mm & \multirow{2}{*}{\multicolumn{2}{|c|}{ Material: }} & \multirow{3}{*}{ Duct/Pipe Insulation } \\
\hline XDim: & & $4277 \mathrm{~mm}$ & & & \\
\hline YDim: & & $790 \mathrm{~mm}$ & \multicolumn{2}{|c|}{ Pset_CoveringCommon } & \\
\hline \multicolumn{2}{|l|}{ Extrusion } & & \multicolumn{2}{|l|}{ Reference: } & Izolace potrubí:Thermal Insulation \\
\hline \multicolumn{2}{|l|}{ OriginX: } & $-20399 \mathrm{~mm}$ & \multicolumn{2}{|l|}{ Rozměry } & \\
\hline \multicolumn{2}{|l|}{ OriginY: } & $-19104 \mathrm{~mm}$ & \multicolumn{2}{|l|}{ Délka: } & $4277 \mathrm{~mm}$ \\
\hline \multicolumn{2}{|l|}{ OriginZ: } & $3120 \mathrm{~mm}$ & \multicolumn{2}{|l|}{ Velikost potrubí: } & $710 \times 500$ \\
\hline \multicolumn{2}{|l|}{ XDirX: } & -1 & \multirow{2}{*}{\multicolumn{2}{|c|}{ Identifikační data }} & \\
\hline \multicolumn{2}{|l|}{ XDirY: } & 0 & \multirow{2}{*}{\multicolumn{2}{|c|}{ Kód sestavy: }} & \\
\hline \multicolumn{2}{|l|}{ XDirZ: } & 0 & & & \\
\hline ExtrusionX: & & $0 \mathrm{~mm}$ & Popis sestavy: & & \\
\hline ExtrusionY: & & $0 \mathrm{~mm}$ & Název typu: & & Thermal Insulation 40mm \\
\hline ExtrusionZ: & & $580 \mathrm{~mm}$ & Materiály a povr & hové úpravy & \\
\hline
\end{tabular}

Figure 5: Information on the selected model element, [authors]

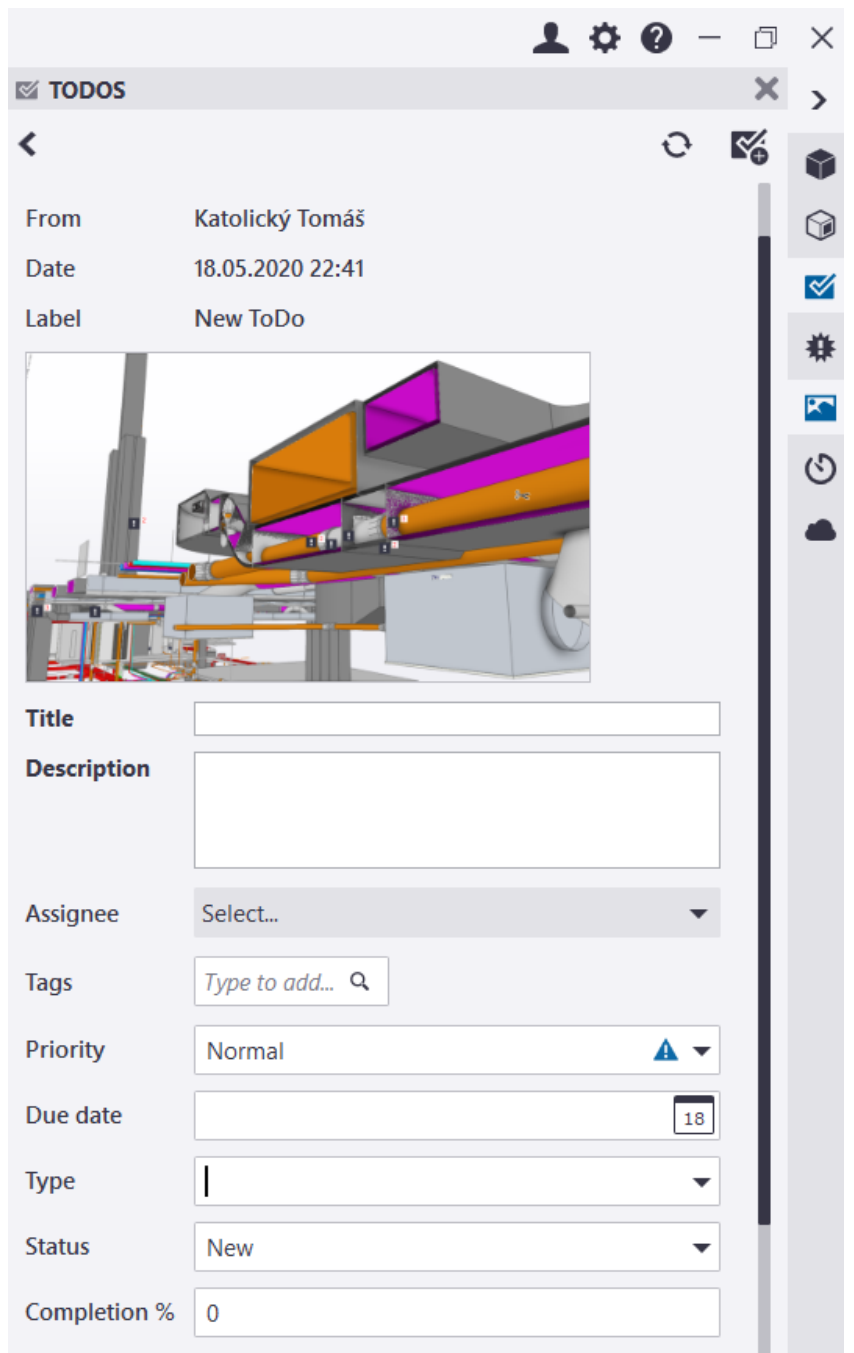

Figure 6: Comments and tasks (ToDos) for the slected clash, [authors] 


\section{Conclusion}

The most important general benefits of building information modeling include improving the control of the construction process and the quality of the resulting construction, saving costs and time throughout the life cycle of the construction, the availability of up-to-date information in one place, improving information for decision-making, improving communication, coordination and cooperation between participants in the construction process. Advantages in the design of MEP are also the possibility of faster and more accurate design, timely detection and resolution of clashes, use of product libraries from manufacturers, easier implementation of changes, possibility of variant solutions and simulations in various conditions, easier transmission of documents and reduction of error rate during updating documentation.

The most important obstacles to building information modeling are the pressure to reduce the price of the construction project, which leads to lower design quality without the possibility of optimization using BIM, financial demands of BIM implementation (SW, process settings, training), lack of qualified technical and management staff with BIM knowledge, persistent habits from 2D documentation and rejection of new technologies, possible unavailable database of products from manufacturers, non-use of BIM method by all process participants.

In the upcoming years, BIM models foresee greater use of data in dimensions 4D (time), 5D (cost), 6D (sustainability), 7D (facility management) so that as many analyses and simulations as possible can be performed in a timely manner, including clash detection of various types. It will be a great advantage to simulate in advance the impact of certain decisions in the implementation of the project on costs, schedule, energy performance of the building, fire protection, occupational safety and health and other related areas.

The future of building information modeling will be influenced by other trends. Greater use of the Internet of Things and Services will bring more detailed data and better possibilities for advanced construction and subsequent management of the building, e.g., timely maintenance, reduced service interventions, acceleration of response time and earlier troubleshooting. Thanks to virtual reality, it will be possible to better explore the real building in conjunction with its digital documentation and consult both images (real and digital) remotely with other experts. Laser 3D scanning drones will provide quantity of accurate information about the actual 3D dimensions of the structure and possible defects for inspection activities. Greater emphasis will be placed on modular construction and prefabrication, which will contribute to reducing costs and speeding up construction, as building elements can be prepared and assembled before delivery to the site. 3D printing technology allows you to quickly create models of future construction and then build from very accurate building elements in a short time.

Building information modelling, together with other technical innovations, is a great opportunity to improve the coordination of HVAC in the preparation of construction projects, to an efficient construction process and, ultimately, to improve the economic results of the whole construction industry.

\section{Acknowledgement}

This work was supported by the Grant Agency of the Czech Technical University in Prague, grant No. SGS19/100/OHK1/2T/11. 


\section{References}

[1] EUBIM TaskGroup. Př́ručka pro zavádění informačního modelování staveb (BIM) evropským veřejným sektorem. Strategická opatření pro zvýšení výkonnosti stavebnictví [online]. 2018. [accessed 20.3.2020]. Available online at: https://www.mpo.cz/assets/cz/stavebnictvi-a-suroviny/bim/2018/4/GROW-201701356-00-00-CS-TRA-00.pdf

[2] Ministerstvo průmyslu a obchodu. Koncepce zavádění metody BIM v České republice [online]. 2017. [accessed 20.3.2020]. Available online at: https://www.koncepcebim.cz/uploads/inq/files/Koncepce zavádění metody BIM v ČR.pdf

[3] BIM Koncepce 2022. Výstupy [online]. Česká agentura pro standardizaci @ 2018-2022. [accessed 18.4.2020]. Available online at: https://www.koncepcebim.cz/439-vystupy

[4] Tech United. BIM Tools. [online]. February 2019. [accessed 20.4.2020]. Available online at: https://www.techunitedllp.com/post/the-5d-model-and-various-dimensions

[5] ČERNÝ, Martin. BIM príručka. Praha: Odborná rada pro BIM, 2013. ISBN 978-80-260-5296-8.

[6] ADEB-VBA. Building Information Modelling - Belgian Guide for the Construction Industry [online]. 2015. [accessed 20.4.2020]. Available online at: http://adeb-vba.be/the-guide-to-bim.pdf

[7] UnitedBIM. BIM Execution Plan (BXP) [online]. 2018. [accessed 20.4.2020]. Available online at: https://www.united-bim.com/bim-execution-plan-bep-guide-for-successful-bep-design-and-execution/

[8] SWAPNESH, Raut, VALUNJKAR, Shriniwas. Improve the Productivity of Building Construction Project using Clash detection Application in Building Information Modeling. International Research Journal of Engineering and Technology, vol. 4, issue 3, pp. 1784-0056. ISSN 2395-0056

[9] SEO, Jung-Ho, LEE, Beak-Rae, KIM, Ju-Hyung. Collaborative Process to Facilitate BIM-based Clash Detection Tasks for Enhancing Constructability. Journal of the Korea Institute of Building Construction. 2012, vol. 13, issue 13, pp. 299-314. ISSN 2233-5706. 